\title{
Clinical, Diagnostic and Therapeutic Implications of Coronavirus ORFab Polyprotein Associated Nsp16 Protein-A Bioinformatics Approach
}

\section{Asit Kumar Chakraborty*}

Associate Professor of Biochemistry, Department of Biochemistry, Oriental Institute of Science and Technology, Vidyasagar University, Midnapore, West Bengal, India

*Corresponding Author: Asit Kumar Chakraborty, Associate Professor of Biochemistry, Department of Biochemistry, Oriental Institute of Science and Technology, Vidyasagar University, Midnapore, West Bengal, India. DOI: 10.31080/ASMS.2020.04.0629
Received: April 06, 2020

Published: May 04, 2020

(C) All rights are reserved by Asit Kumar

Chakraborty.

\begin{abstract}
COVID-19 infections are rapidly spreading worldwide with more than 100000 death and thus understanding the molecular mechanism of tropism of human cells is an urgent need for drug design. We have described here a bioinformatics approach to predict the functional aspects of non-structural nsp16 protein of Corona virus. The COVID-19 7096 AA large polyprotein was degraded into sixteen proteins and last nsp16 protein was found an RlmE type rRNA Methyltransferase. Nsp16 has no similarity to bacterial RlmABCD but has 25 percent similarity to the bacterial RlmE MTase protein which methylates the U2551 2-hydroxy group of Ribose. The nsp16 proteins of different corona viruses like Covid-19, bat-coronavirus, SARS and MERS have strong homology. Mrm2 and Dim1 like yeast and mammalian rRNA methyltransferases have 26-33 percent homologies but not with 2'-0-capping MTase as reported previously. Rrp8 MTases also has no similarity to nsp16. We postulated that mitochondrial rRNA methylation of bronchial cells were mediated by the nsp16 protein causing inhibition of protein synthesis due to poor assembly of aminoacyl-tRNA or mRNA and peptidyl transferase at the PTC. This is one of the new molecular mechanism of corona virus cellular tropism and different than ACE-2 mediated blockage of cellular signalling to inhibit aldesterone biosynthesis with abnormal Na+ ions in cells. We also designed primers based on nsp16 cDNA sequence (nt 20659-21552, accession no MT121215) specific for Covid-19 diagnosis by RT-PCR. Antisense and ribozyme against Nsp16 may be another molecular approach to stop Coronavirus translation using nano-carrier drug delivery. Whereas phyto-chemicals from Indian medicinal plants may be studied to stop functions of Nsp16 RlmE Methyltransferase as another therapeutic approach against Coronavirus pathogenesis.
\end{abstract}

Keywords: Covid-19; rlmE MTase; New Drug Target; Corona Diagnosis; Corona Pandemic

\section{Introduction}

Coronaviruses (family Coronaviridae) are enveloped viruses with a largest positive sense, single-stranded RNA genome of $30 \mathrm{~kb}$ $[1,2]$. On genetic and antigenic criteria, CoVs have been organised into three groups: $\alpha$-CoVs, $\beta$-CoVs, and $\gamma$-CoVs [3-5]. Coronaviruses primarily infect birds, mammals and human, causing a variety of lethal respiratory diseases resembling the common cold, to lower respiratory tract infections such as bronchitis, pneumonia, and even severe acute respiratory syndrome (SARS). In recent years, coronaviral research must be augmented due to pandemic severe respiratory illnesses outbreaks claiming $>100000$ deaths [6]. Covid-19 virus enter cells through ACE2 receptor-mediated endocytosis. The receptor ACE2, was abundant in lungs AT2 alveolar epithelial cell as well as cells in the kidney, heart and blood vessels [7]. One of the known regulators of endocytosis is the AP2associated protein kinase-1 implicated novel target for therapeutic intervention. Figure 1 demonstrated the blockage of ACE- 2 receptors prevents the aldosterone synthesis and thus deregulating $\mathrm{Na}^{+}$ absorption, blood pressure and normal renal function. We suggested a new role of cellular tropism by inhibiting cellular protein synthesis.

Discovery of new molecular target is urgent need for covid-19 and we target here rRNA methylase. There are more than 20 differ-

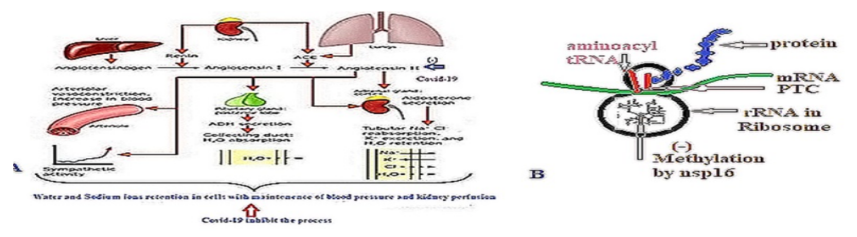

Figure 1: (A) Renin-Agiotensin System and problem associated with covid-19 binding to ACE-2 receptors preventing such signalling. (B) nsp16 methylates 21S rRNA in mitoribosome inhibiting protein synthesis. Hypothesis is due to loss of mitochondrial proteins oxidative phosphorylation may be prevented causing sudden death of Corona-infected patients.

ent classes of rRNA methyltransferases that modify 16S rRNA, 23S rRNA and tRNAs in bacteria but mammalian methyltransferases are more diverged [8]. Cfr and Erm methyltransferases are known for erythromycin and linezolid drug resistance in bacteria and others like Rmt, ArmA and Rlm methyltransferases are involved in ribosome biogenesis as well as modulator of drug resistance (Figure 2). Different isomers of Rlm (A-N) rRNA methyltransferases methylate at various positions of bacterial 23S rRNA conferring multi-resistant to macrolides and ketolides like erythromycin, telithromycin, and solithromycin. RImA ${ }^{\mathrm{II}}$ MTase has preference to $\mathrm{N}_{1}$ of G748 of 23S rRNA [9]. RlmB MTase (protein id. BAI33654) modifies G2251 of 23S rRNA [10,11] while RlmC modifies m5U747 
in 23S rRNA and RImD is specific for m5U1939 [12]. RlmE (protein ids. RXP80948 and TJL68081) and RlmF (prtein ids. TZE44659; BAI32636) 23S rRNA 2'-O-U2552 methyltransferase also has detected in E. coli chromosome and plasmids. RlmE has similarity to RlmC but diverged in other isomers. RlmG (protein id. CRY88590) methylates at $\mathrm{N}_{2}$ of G1835, while RlmH (protein id. QBF38433) methylates pseudo-uridine $\mathrm{N}_{3}$ at position 1915 and $\mathrm{RlmN}$ (protein id. QBF37927) methylates $\mathrm{C}_{2}$ at A2503. RlmH (UbeA) catalyzes the transfer of a methyl group from S-adenosyl-L-methionine (SAM) to the nucleotide at position $\mathrm{m} 3 \psi 1915$ of E. coli $23 \mathrm{~S}$ rRNA . RlmI (protein id. QEP80348; MHW78000) also methylates E. coli $23 \mathrm{~S}$ rRNA and RlmJ catalyzes the m6A2030 methylation of 23S rRNA during ribosome biogenesis in Escherichia coli. The active site of RlmJ with motif IV sequence 164DPPY167 is more similar to DNA m6A MTases than to RNA m6,2A MTases and the enzyme crystal structure was determined [13]. RlmM (YgdE; EC:2.1.1.186) enzyme catalyzes the SAM-dependent 2' O-ribose methylation of C2498 in 23S rRNA of Escherichia coli. RlmN installs a methyl group at the $\mathrm{C} 2$ position of $\mathrm{A} 2503$ of $23 \mathrm{~S}$ rRNA, while it also methylates at tRNA at nucleotide A37 giving linezolid resistance in $S$. aureus [14]. RlmK/L (protein ids. MHY78137 and BAI29841) and both recombined enzyme (YcbY) adds the m7G2069 and m2G2445 methylations in Escherichia coli 23S rRNA (Kimura., et al. 2012). TlyA from Mycobacterium tuberculosis has proven 2'O-ribose MTase activity on $\mathrm{C} 1409$ of $16 \mathrm{~S}$ rRNA and C1920 of 23S rRNA. The ${ }^{8}$ A2503 modification by Cfr in vivo leads to a decreased level of modification of $\mathrm{C} 2498$ by RlmM indicating domain $\mathrm{V}$ in presence of the Cfr-catalyzed methylation prefers a conformation where the $2^{\prime}-0$ of C2498 is no longer accessible for RlmM. In the mature ribosome, A2503 stacks between A2059 and G2061 at the opposite side of the peptidyl transferase loop, and possibly the methylation, apart from sterically hindering antibiotic binding, also increases the stability of the stacked structure [14]. However, ribose 2'-0methylation similar to RImB methylation of 2'-O of guanine, is the most abundant rRNA chemical modification to be essential for accurate and efficient protein synthesis in cells and has no role in drug resistance. Such enzymes are involved in capping of eukaryotic mRNA and modification of rRNAs and tRNAs. Human CMTr1/2 2'O-linked methyltransferase has been purified and characterized [15]. Interestingly, Rlm MTases were rarely sequenced in plasmids of Enterobacteriaceae but in Pseudorhodobacter sp 1584kb unnamed plasmid indeed contained RlmF (EC:2.1.1.181) and RlmB methyltransferases and other RNA modifying enzymes (accession no. CP039965). The RlmD, RlmH and RlmN 23S rRNA Methyltransferases in large plasmid of Acinetobacter baumannii (accession no. CP035931, $1024 \mathrm{~kb}$ ) was reported. Surely, roles of Rlm family methyltransferases in multi-resistance remains controversial at this point. Although it has been reported that U1939 methylation is involved in reproducible resistance to fusidic acid and capreomycin. Mitochondrial rRNA of yeast contains three modified nucleotides: a pseudouridine at 2918, two 2'-0- methylated ribose at G2270 and U2791 located near the peptidyl center. Mrm2p is the orthologue of FtsJ/RsmJ which methylates U2791 of 21S rRNA of mitochondria in yeast and mammalian cells. Di-methyl Adenine modification in yeast was mediated by Dmt1 like $\mathrm{n} 6$ adenine of yeast and Chlamydomonas mitochondria (protein id. EDP08643). FtsJ2 and
Mrm2 methyltransferases are involved in 21S rRNA methylation in yeast as well as in human $[16,17]$. However, some 2'-0-MTases were also implicated in capping of mRNA at the $5^{\prime}$-end by methyl $N^{\top}$-methylguanosine linked via an inverted $5^{\prime}-5^{\prime}$ triphosphate bridge to the 5'-terminal nucleoside of the transcript [15]. Uncapped RNAs, such as nascent viral transcripts, may be detected as 'non-self' by the host cell, triggering an antiviral innate immune response through the production of interferons. Therefore, many viruses that replicate in the cytoplasm of eukaryotes have evolved 2'-O-methyltransferases $(2 '-O$ MTases) to autonomously modify their mRNAs $[18,19]$. Virus-encoded 2'-O MTase enzymes involved in the synthesis of the RNA cap structure are different from those of host cells. As a consequence, these pathogenic cap-forming enzymes are potential targets for antimicrobial drugs [20]. Such human and rat capping MTases were distinct and no similarity to nsp16 or covid-19 RlmE MTase [21]. Thus, the report on capping 2'-0 methylase activity of nsp16 (nsp13 in case of SARS) is interesting and likely a contamination of other methylase activities [22] but nsp16 has no similarity to mammalian 2'capping methyltransferase [15].

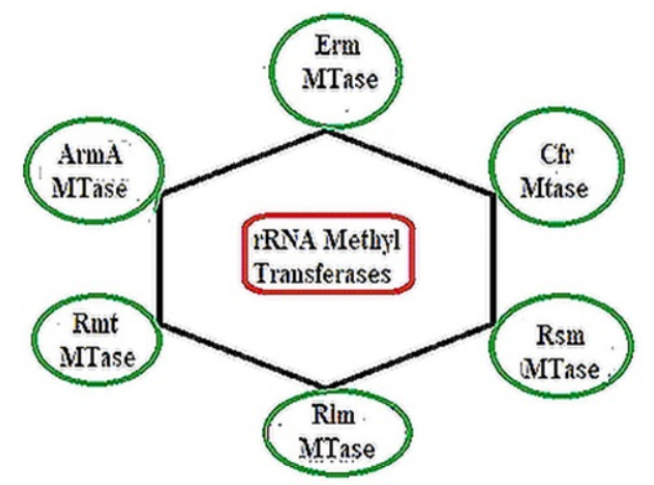

Figure 2: Different types of rRNA Methyl Transferases characterized in bacteria. But nsp16 methyltransferase is unique for Coronavirus. We propose nsp16 is rlmE type 2'0-Ribose 21S rRNA methyltransferase but not 2'-0 capping mRNA methyltransferase as reported erlier.

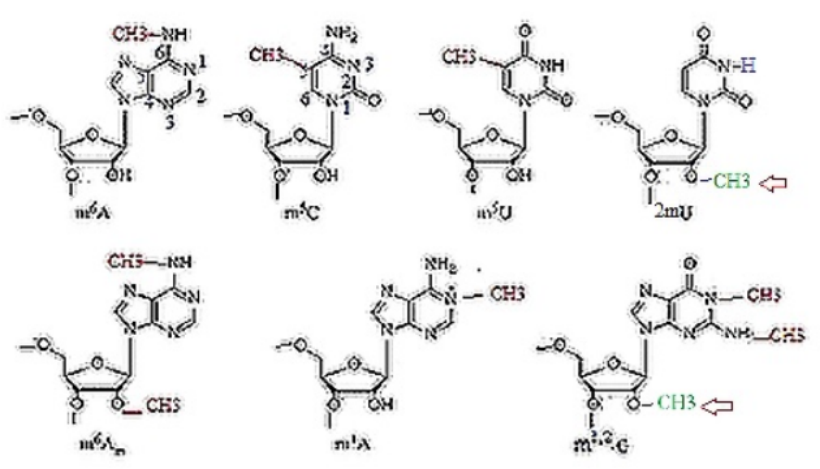

Figure 3: Methylating positions in RNA by different rRNA Methyl Transferases. Nsp16 methylates Uridine 2'-O-Ribose (green).

\section{Materials and Methods}

The BLAST search was done using web portal www.ncbi.nlm. nih.gov/blast and retrieve of covid-19 and other corona viruses 
99

cDNA sequences were done using web portal www.ncbi.nlm.nih. gov/nucleotide or protein. NCBI Primer Design Software was used for primer selection and Oligoanalyzer 3.2 software was used to analyze primer dimmer and hairpin structure. Multalin Software and CLUSTAL Omega Software were used to multiple align of protein sequences and NCBI BLAST seq- 2 analysis portal used to analyze homology between two sequences. NCBI pubmed portal (www.ncbi.nlm.nih.gov/pubmed) used to retrieve references and papers.

\section{Result}

We have analyzed the covid-19 genome and the proteins expressed by (+) sense $30 \mathrm{~kb}$ rNA genome (Figure 4 ). The polyprotein ORF1an is 7081 aa and last protein designated as nsp16 (Figure 4B) which has similarity to the E. coli RlmE methyltransferases which methylates Uridine 2551 2'-0-Ribose of $23 \mathrm{~S}$ rRNA (Figure 1C). Other non-structural proteins of large covid-19 polyprotein was shown in table 1. In table 2, we have demonstrated the plasmidmediated (panel-1) localization of different Rlm methyltransferases as well as other rRNA mehyl transferases (panel-3 involved in drug resistance through mdr gees and drug efflux genes (Table 2, panel-4). The Treponema sp RlmE also has some homology as demonstrated in figure 5 . We searched different nsp16 proteins in variety of acute respiratory corona viruses and multi-align study (Figure 6A) demonstrated their homology and figure 6B demonstrated their phylogenic relation showing human covid-19 nsp16 was distinct than Avian or Feline or Canine Corona viruses. We have compared nsp16 protein with the many eukaryotic rRNA methyl transferases and found $30-33 \%$ homology at different regions showing some relations among Mrm2, Bud23 and Dim1 methyl transferases (Figure 7A) with best fit region also has predicted by multi-alignment (Figure 7B) but we also showed that 2'-O-Ribose Capping MTases were distinct and had no similarity to nsp16 (Figure 7C). Mitochondrial Mrm2 2'-O-ribose methyltransferase required for methylation of U2791 in 21S rRNA. Such search confirmed nsp16 is a distinct rRNA methyl transferase and may have specificity to mitoribosome.

\begin{tabular}{|l|c|c|}
\hline Proteins & Function-1 & Function -2 \\
\hline Nsp1 & Transcription factor & Inhibits translation \\
\hline Nsp2 & Binds proinhibitin proteins & $?$ \\
\hline Nsp3 & Transmembrane protease & ADRP activity \\
\hline Nsp4, 5, 6 & Transmembrane protease & proteases \\
\hline Nsp7 & $\begin{array}{c}\text { Forms hexadecameric and } \\
\text { DNA binding }\end{array}$ & $\begin{array}{c}\text { RNA polymerase } \\
\text { open complex }\end{array}$ \\
\hline Nsp8 & RNA primase & $?$ \\
\hline Nsp9, 10 & RNA binding & Co-factor nsp14 \\
\hline Nsp12 & $\begin{array}{c}\text { RNA dependent RNA poly- } \\
\text { merase }\end{array}$ & \\
\hline Nsp13 & RNA helicase & 5'-phosthatase \\
\hline Nsp14 & Exoendonuclease & $?$ \\
\hline Nsp15 & Endoribinuclease & $?$ \\
\hline Nsp16 & RNA biding & RlmE MTase \\
\hline
\end{tabular}

Table 1: Non-structural proteins of corona virus (protein id. QII57165).

\begin{tabular}{|c|c|c|c|}
\hline $\begin{array}{c}\text { Bacteria } \\
\text { types }\end{array}$ & $\begin{array}{l}\text { Plasmid: } \\
\text { size and } \\
\text { Accession } \\
\text { number }\end{array}$ & $\begin{array}{l}\text { MTases protein } \\
\text { id (Cfr, Erm, } \\
\text { Arm, Dcm, } \\
\text { Dam) }\end{array}$ & $\begin{array}{c}\text { Other mdr } \\
\text { genes, toxin } \\
\text { genes and metal } \\
\text { resistant genes }\end{array}$ \\
\hline S. $a$ & $\begin{array}{c}\text { pSA-01; } 63.5 \\
\text { kb; } \\
\text { KX274135 }\end{array}$ & $\begin{array}{c}\text { Cfr=ATB18028 } \\
\text { ErmT=ATB18031 } \\
\text { ErmB=AR044757 }\end{array}$ & $\begin{array}{c}\text { tetL=AR044726 } \\
\text { aacA- } \\
\text { aphD=AR044756 } \\
\text { aadD=AR044732 }\end{array}$ \\
\hline $\begin{array}{l}\text { K. } \\
\text { pneu- } \\
\text { moniae }\end{array}$ & $\begin{array}{l}\text { pK-109-R; } \\
156.5 \mathrm{~kb} ; \\
\text { KX029331 }\end{array}$ & $\begin{array}{c}\text { RmtG=APD70474 } \\
\text { RsmH=APD70476; } \\
\text { Dcm=APD70554 }\end{array}$ & $\begin{array}{l}\text { tetC; arr3; catB3; } \\
\text { strB; StrA; QacE; } \\
\text { sul1; blaCTX-M2; } \\
\text { blaOXA1; aac6'-1b }\end{array}$ \\
\hline $\begin{array}{l}\text { Crono- } \\
\text { bacter } \\
\text { sakazakii }\end{array}$ & $\begin{array}{c}\text { pCsaCS931a; } \\
\text { 4194kb; } \\
\text { CP027108 }\end{array}$ & $\begin{array}{c}\mathrm{RlmC}=\mathrm{AXX} 00175 \\
\mathrm{RlmK} / \\
\mathrm{L}=\mathrm{AXX00103} \\
\mathrm{RlmI}=\mathrm{AXX} 00086\end{array}$ & $\begin{array}{c}\text { mdtA, macA/B, } \\
\text { MFS, RND }\end{array}$ \\
\hline $\begin{array}{l}\text { Salm } \\
\text { la en }\end{array}$ & $\begin{array}{l}\text { P2, } \\
\text { LN8 }\end{array}$ & \begin{tabular}{|c|} 
RsmE/ \\
I=CRY88440/627 \\
RlmG $/$ \\
M=CRY88590/328 \\
\\
TrmB=CRY88455
\end{tabular} & $\begin{array}{r}\mathrm{Bla}_{\mathrm{MBL}}=\mathrm{CRY} \\
\text { AcrE, s| }\end{array}$ \\
\hline $\begin{array}{l}\text { Pseudo- } \\
\text { rhodo- } \\
\text { bacter sp }\end{array}$ & $\begin{array}{l}\text { P1, 1584kb; } \\
\text { CP039965 }\end{array}$ & $\begin{array}{l}\mathrm{R} \operatorname{lm} F=Q \operatorname{CO57550} \\
\mathrm{R} \operatorname{lmB}=\mathrm{QCO57183} \\
\mathrm{RsmB}=\mathrm{QCO56847}\end{array}$ & $\begin{array}{c}\text { Multidrug efflux } \\
=\text { QCO56662, } \\
\text { QCO57496; } \alpha \beta \\
\text { Hydrolase = } \\
\text { QC058033 }\end{array}$ \\
\hline
\end{tabular}

Table 2: Rmt methyltransferases in bacterial plasmids causing alteration of ribosome structure and protein synthesis.

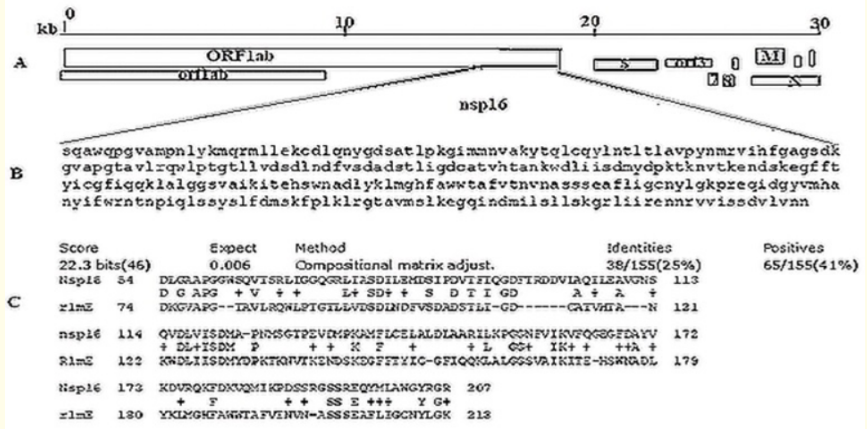

Figure 4: Localization of RlmE methyltransferases (nsp16) on the RNA geneme of Corona Virus (A), its amino acid sequence (B) and compare with bacterial RImE protein.

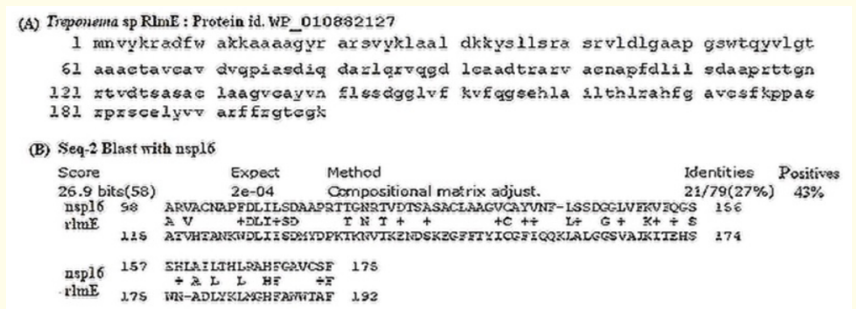

Figure 5: Seq-2 alignment between nsp16 of human Corona virus and Treponema sp RImE MTase. Such little homology was not found with 20 different types of rRNA methyltransferase. 


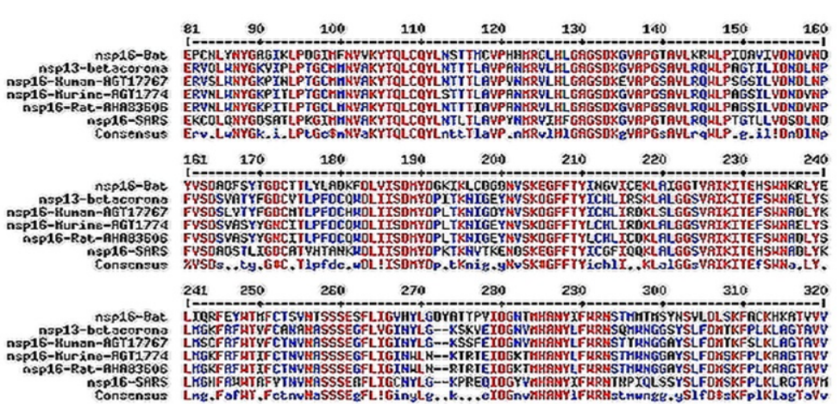

Figure 6a: Multi-alignment of nsp16 proteins of different corona viruses showing strong homologies.

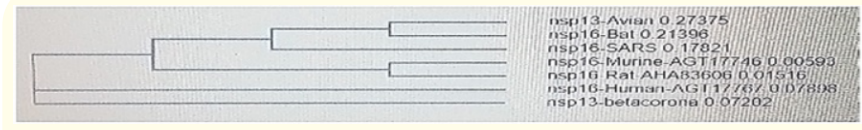

Figure 6b: Phylogenetic analysis of RlmE MTases from different species. Human coronavirus rlmE methyltransferase appeared distinct.

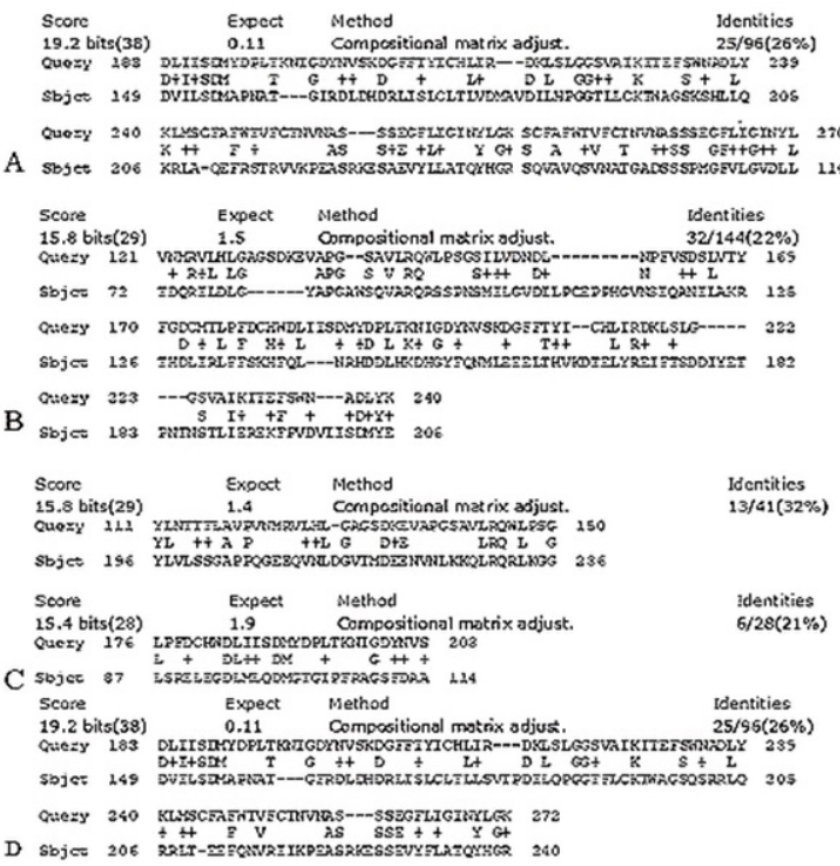

Figure 7a: BLAST Seq2-alignment among eukaryotic rRNA Methyl Transferases and nsp16 protein of corona virus. (A) Rat RlmElike protein (accession-NP_001100595), (B) Yeast Mrm2 MTase (accession-QHB08519) that methylates U2791 on 21S mitochondrial rRNA, (C) Yeast Bud23 MTase (accession-QHB07184) and (D) human Mrm2 MTase (accession- NP_037525) were compared with nsp16 of corona virus.

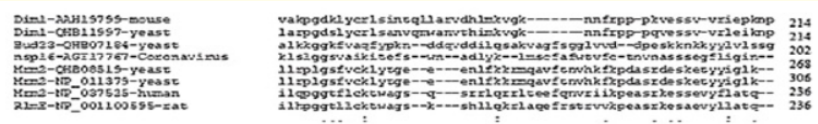

Figure 7b: Multialignment of different eukaryotic and corona virus rRNA methyl transferase showing best fit region but poor homology.

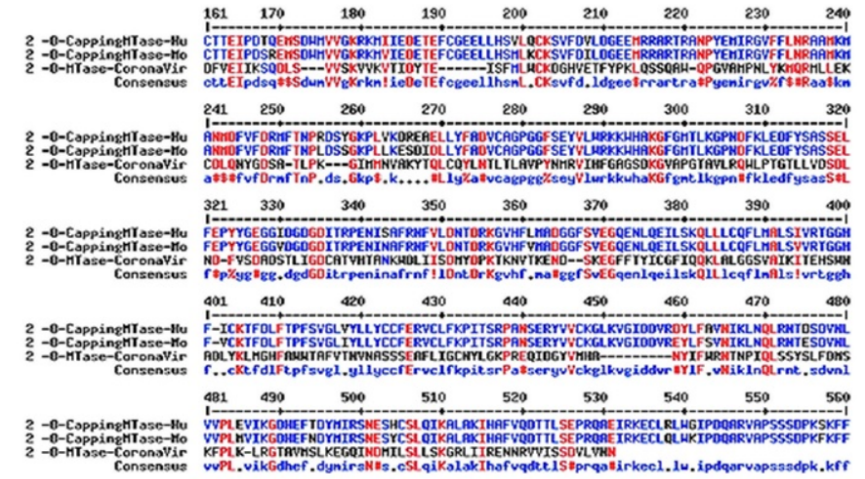

Figure 7c: No similarity of nsp16 RmtE protein with eukaryotic capping 2'-0-MTase.

Further, we designed the covid specific primers for the RT-PCR to detect the virus load during pathogenesis. The cDNA sequence nt. 20659-21552 (accession no. MT121215) was used to design four pairs of primers using NCBI Primer Design Software (Figure 8). Individual forward and reverse primer were BLAST searched and primer pair-4 appeared more specific for the diagnosis of covid-19 (Figure 9). The primers were further analyzed by OligoAnalyzer 3.2 Software to check the hairpin structure (Figure 10) and Dimmer formation (Figure 11). BLAST search indicated covid-19 specificity. Similarly, OligoAnalyzer analysis proved the melting point of hairpin structures varies between -12 to +23 degree centrigrade well below of Tm 60 degree centrigrade. Also dimmer formation with self or with reverse primer (pair-4) shown in figure 11 with delta-G -3 to- $5 \mathrm{Kcal} /$ mole reflecting a very good primer pair. GC content between $47-50 \%$ was also very good for RT-PCR as $1^{\text {st }}$ strand synthesis with reverse transcriptase occurred at 48 degree centrigrade. The BLAST search of forward oligo gave 100 covid genomic sequences with $100 \%$ specificity and no human sequence was detected in such extended search with 5000 genomic sequences (Figure 9). Other oligo pairs (primer pair-1) might be good to use but also hybridized to the SARS and MERS Coronaviruses [23]. We made restriction enzyme analysis (Figure 12A) showing single hexa-cutter enzymes and have chosen BglII, NheI and SspI enzymes (Figure 12B) for analysis of PCR product (564 bp) giving a unic pattern of agarose gel picture when restricted PCR products were compared with uncut RT-PCR product (Figure 12C). This help any

\begin{tabular}{|c|c|c|c|c|c|c|}
\hline Forward primer & $\begin{array}{l}\text { Sequence }(* \rightarrow 3) \\
\text { TCTAGTCAAGCGTGGCAACC }\end{array}$ & $\begin{array}{l}\text { Template strand } \\
\text { Flus }\end{array}$ & $\begin{array}{l}\text { Length } \\
20\end{array}$ & $\begin{array}{l}\text { Start } \\
19\end{array}$ & $\begin{array}{l}\text { Stop } \\
38\end{array}$ & $\begin{array}{l}\mathrm{Tm} \\
60.32\end{array}$ \\
\hline Rererse primuer & ATAGCCACCGAACCTCCAAG & Minøz & 20 & 524 & & 59.46 \\
\hline $\begin{array}{l}\text { Produet length } \\
\text { Primer pair } 2 \\
\end{array}$ & 506 bp & & & & & \\
\hline & Sequerese $\left(5^{\prime} \rightarrow 3^{\prime}\right)$ & Teuplate strand & Leogth & & & \\
\hline Forwand primer & ACAATCTAGTCAAGCGTGGCA & Fitus & & 15 & 35 & $60 . \infty$ \\
\hline Reverse primer & OGCGTGGTTECCARGAIRA & & & & & \\
\hline \multirow{2}{*}{$\begin{array}{l}\text { Produset leneth } \\
\text { Primer pair } 3\end{array}$} & $653 \mathrm{bp}$ & & & & & \\
\hline & Sequence $\left(5->3^{3}\right)$ & T amplate str.und & Length & Start & Stop & $T_{n}$ \\
\hline Forwand priver & AACCGGGTGTTGCTATCCCT & Mos: & 20 & 35 & 54 & 62.14 \\
\hline Reverse primer & TAITMGTCGOGTGGTIMGCC & Minus & 21 & & & \\
\hline $\begin{array}{l}\text { Produst leagth } \\
\text { Primer pair } 4 \\
\end{array}$ & $641 \mathrm{bp}$ & & & & & \\
\hline & Sequence $(F-1)$ & Template strand & Length & Sert & Stop & $\mathrm{Tm}_{\mathrm{m}}$ \\
\hline wer & FCTATGCCTAATCI & & & & & \\
\hline & GTAACAAAGGCTGTCCACCA & Minus & 20 & 602 & 583 & $\$ 8.02$ \\
\hline oduct le & & & & & & \\
\hline
\end{tabular}

Figure 8: Selection of nsp16 specific primer pairs for RT-PCR. Primer pair 4 was Covid-19 specific and analyzed further 


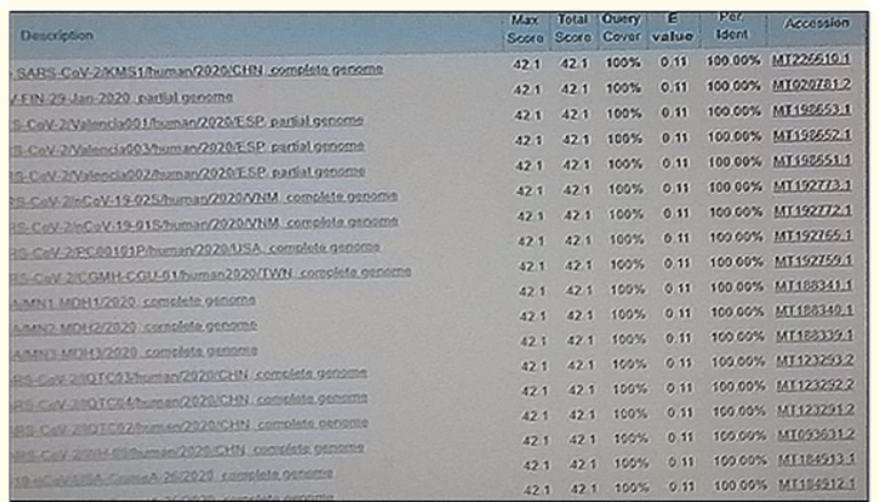

Figure 9: BLAST search result of nsp16F4 oligo sequence showing covid-19 specificity
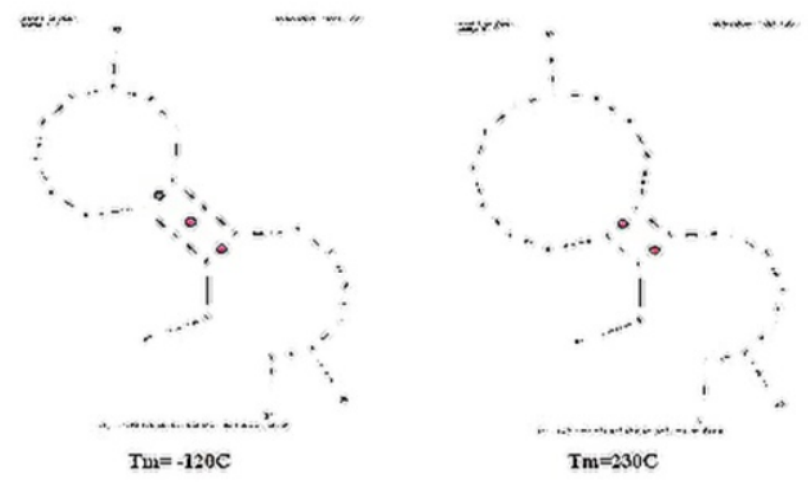

Figure 10: Hairpin formation of nsp16F4 indicating low Tm of such self complex.
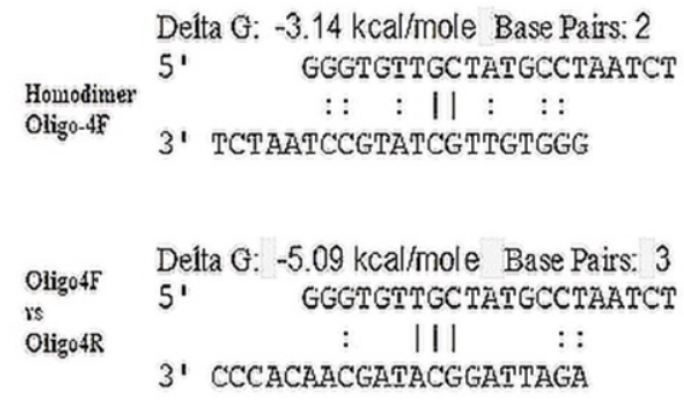

Figure 11: Dimmer formation of nsp16F4 and nsp16R4 primers showing low melting point of such dimmers. F means forward primer and R means Reverse primer. Nsp16 means coronavirus RlmE 2'-O-Ribose Uridine ${ }^{2551}$ Methyl Transferase.

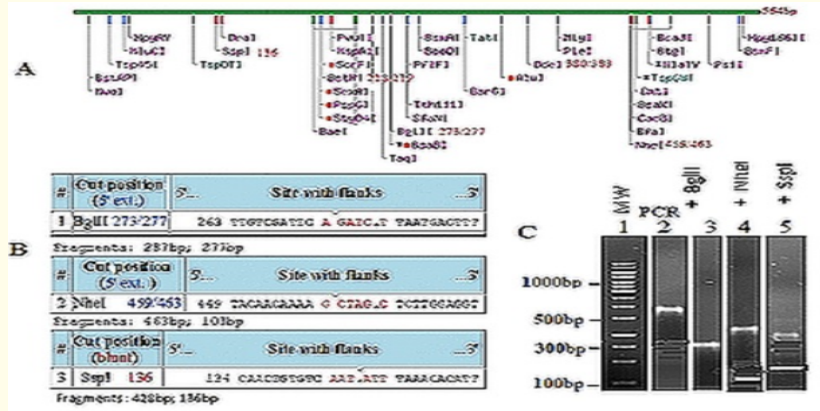

Figure 12: Analysis of the PCR product with nspF4/nspR4 primers. Restriction map of the PCR fragment (A); the 3 hexacutter single cut enzyme were chosen (B) and a 1\% agarose gel in1xTAE buffer for $2 \mathrm{hrs}$ at $50 \mathrm{~V}$ stained with EtBr and under UV illumination (a prototype picture was made). graduate student can see the data and can compare with own to sure that RNA is for COVID-19.

\section{Discussion}

We explained the possible role of RlmE methyltransferase (nsp16) in corona virus pathogenesis being a molecular target for drug design. The study is based on homology of nsp16 to bacterial RImE methyltransferases and such enzyme was located in many coronaviruses like SARS and MERS. Viral capping MTase was shown as molecular target and thus nsp16 MTase could be an ideal target to block cellular tropism of covid-19. Three regions of ORF1ab polyprotein of covid-19 showed some homologies at the level of 20-25\% (aa 1479-1569; aa3290-3360 and aa 4895-4935) with human capping MTase but not with nsp2 protein suggesting Covid-19 may code such enzyme [24,25]. From such analysis we concluded that nsp16 RImE was not involved in mRNA capping [26,27]. But if human mitoribosome (21S and 12S rRNAs) be methylated by nsp16 protein is an interesting question but 23S rRNA prototype rRNA in human nucleus is 28S rRNA and some MTases (cfr and emrB) have 23S rRNA specificity rather than 16S rRNA (Figure 3).

We claim that our study is important for unknown microbe like covid-19 that is claiming > 90000 lives due to lack of drug. Nonstructural viral proteins are ideal for drug discovery understanding molecular mechanism of pathogenicity. It was demonstrated that $\mathrm{P7}$ protein of hepatitis $\mathrm{C}$ virus was the target of hexamethylene amiloride [28] whereas the rotavirus NSP4 viroporin domain was shown as calcium-conducting ion channel [29]. Coronavirus envelope protein or nucleocapsid protein have shown as molecular targets [30]. Nigella sativa, Anthemis hyalina and Citrus sinensis phytochemicals have some antiviral effect on Corona viruses replication [31]. Such anti-viral drug screening against covid-19 is an urgent need to control deadly pandemic nature of pathogenesis [32]. Various host factors have been postulated in the literature and need more elaborate study for drug design [33,34]. Targeting cellular autophagy may be one such application to control covid-19 mRNA genome release into cell cytoplasm [35]. Natural products have shown to regulate microbes and became good drugs controlling superbug bacteria, malaria and cancer [36-39]. The 7a protein of Coronavirus has shown to induce apoptosis by caspase-dependent pathways and thus antibody against 7 a protein may be a drug against viral pathogenesis [40]. Interferon-alpha2b and ribavirin improve outcome in MERS-CoV-infected rhesus macaques giving a hope for the treatment of Covid-19 [41].

We have clearly demonstrated that nsp16 is a RlmE type methyl transferase that may methylates 21S rRNA of mitochondria but may be 28S rRNA of human bronchial cells also be methylated by nsp16 protein. Bronchial cells with ACE-2 receptors are target for Covid-19 and methylation of rRNAs in such target cells as well as kidney and heart cells may be possible causing abnormal protein synthesis. Such methylation may favours viral protein synthesis inhibiting cellular protein synthesis that have shown in many viral infections (Figure 4). In truth stopping Rennin-Angiotensin pathway (Figure 1) for aldosterone synthesis causes abnormal $\mathrm{Na}^{+}$ions in cells lowering blood pressure and kidney function. Covid-19 RlmE type MTase has never be implicating in pathogenicity and thus we 
have discussed a new direction of cellular tropism of Corona viruses. Nsp16 MTase has some similarity to the mmr2 and Dim1 rRNA methyl transferase of yeast and mammals (Figure 7). Yeast Rrp8 23S rRNA MTase has poor similarity to nsp16 but no similarity with human Rrp8 protein (data not shown). The primers designed (Figure 8) using Coronavirus rlmE gene sequence may be used for diagnosis and therapeutic discovery in the future. Heterogeneous phyto-antibiotics, gene therapy, anti-sense and ribozyme technology and nano-drug carriers may be future medicine against Covid-19 [36,42-45]. Astonishingly, nsp16 has homology to S1 ribosomal protein indicating its affinity to mitoribosome inhibiting ribosome turn over and protein synthesis.

\section{Conclusion}

We confirmed Nsp16 protein of Coronavirus as RlmE MethylTransferase which might be methylate Uridine 2'-Ribose of 21S rRNA of host mitochondria leading to alteration of mitoribosome structure and hence inhibition of protein synthesis. We hypothesized that sudden inhibition of mitochondrial oxidative phosphorylation in human bronchial and heart cells due to over expression of viral 2'-0 ribose Uridine 2551/2791 Methyltransferase was one of the main reason of Coronavirus tropism.

\section{Acknowledgement}

I thank Dr. Parthapratin Chakravorty of Raja N L Khan Women's College for encouraging covid-19 research.

\section{Conflict of Interest}

No conflict of interest.

\section{Ethical Issues}

No patient was selected in this bioinformatics research.

\section{Bibliography}

1. Woo PC., et al. "Coronavirus diversity, phylogeny and interspecies jumping". Experimental Biology and Medicine 234.10 (2009): 1117-1127.

2. Woo PC., et al. "Comparative analysis of complete genome sequences of three avian coronaviruses reveals a novel group 3c coronavirus". Journal of Virology 83.2 (2009): 908-917.

3. Dominguez SR., et al. "Isolation, propagation, genome analysis and epidemiology of HKU1 betacoronaviruses". Journal of General Virology 95.4 (2014): 836-848.

4. Lau SK., et al. "Discovery of a novel coronavirus, China Rattus coronavirus HKU24,from Norway rats supports the murine origin of Betacoronavirus 1 and has implications for the ancestor of Betacoronavirus lineage A". Journal of Virology 89.6 (2015): 3076-3092.

5. Lu G., et al. "Bat-to-human: Spike features determining 'host jump' of coronaviruses SARS-CoV, MERS-CoV, and beyond". Trends in Microbiology 23.8 (2015): 468-478.
6. Liu DX., et al. "Accessory proteins of SARS-CoV and other coronaviruses". Antiviral Research 109 (2014): 97-109.

7. Zhao Y., et al. "Single-cell RNA expression profiling of ACE2, the putative receptor of Wuhan 2019-nCov". Bio Rxiv (2020).

8. Bauerle MR., et al. "Mechanistic diversity of radical S-Adenosyl methionine SAM-dependent methylation". Journal of Biological Chemistry 290 (2015): 3995-4002.

9. Jiang Y., et al. "Unveiling the structural features that determine the dual methyltransferase activities of Streptococcus pneumonia RlmCD". PLOS Pathogens 14.11 (2018): e1007379.

10. Lovgren JM and Wikstrom PM. "The rlmB gene is essential for formation of Gm2251 in 23S rRNA but not for ribosome maturation in Escherichia coli". Journal of Bacteriology 183 (2001): 6957-6960.

11. Michel G., et al. "The structure of the RImB 23S rRNA methyltransferase reveals a new methyltransferase fold with a unique knot". Structure 10 (2002): 1303-1315.

12. Madsen CT., et al. "Identifying the methyltransferases for m5U747 and m5U1939 in 23S rRNA using MALDI mass spectrometry". Nucleic Acids Research 31 (2003): 4738- 4746.

13. Punekar AS., et al. "Structural and functional insights into the molecular mechanism of rRNA m6A methyltransferase RlmJ". Nucleic Acids Research 41.20 (2013): 9537-9548.

14. Toh SM., et al. "The methyltransferase $\mathrm{YfgB} / \mathrm{RImN}$ is responsible for modification of adenosine 2503 in 23S rRNA". RNA 14 (2008): 98-106.

15. Smietanski M., et al. "Structural analysis of human 2'-0 ribose methyltransferases involved in mRNA cap structure formation". Nature Communications 5 (2014): 3004.

16. Ching YP., et al. "Identification and characterization of FTSJ2, a novel human nucleolar protein homologous to bacterial ribosomal RNA methyltransferase". Genomics 79.2 (2002): 2-6.

17. Lee KW and Bogenhagen DF. "Assignment of 2'-0-methyltransferases to modification sites on the mammalian mitochondrial large subunit $16 \mathrm{~S}$ ribosomal RNA (rRNA)". Journal of Biological Chemistry 289.36 (2014): 24936-24942.

18. Egloff MP., et al. "An RNA cap (nucleoside-2'-0-)methyltransferase in the flavivirus RNA polymerase NS5: crystal structure and functional characterization". The EMBO Journal 21 (2002): 2757-2768.

19. Werner M., et al. "2'-0-ribose methylation of cap2 in human: function and evolution in a horizontally mobile family". Nucleic Acids Research 39 (2011): 4756-4768.

20. Belanger F., et al. "Characterization of hMTr1, a human Cap1 2'-0-ribose methyltransferase". Journal of Biological Chemistry 285.43 (2010): 33037-33044. 
21. Mungall AJ., et al. "The DNA sequence and analysis of human chromosome 6". Nature 425.6960 (2003): 805-811.

22. Von Grotthuss M., et al. "mRNA cap-1 methyltransferase in the SARS genome". Cell 113 (2003): 701-702.

23. Chakraborty AK., et al. "Universal Primer Design for the Detection of Diverged CTX-M Extended Spectrum $\beta$-Lactamases (ESBL) That Give Penicillin and Cephalosporin Resistance During Superbug Infections". In book "Biotechnological Applications in Human Health" Editors: Sadhukhan and Premi, Springer-Nature Singapore Pte Ltd, Chapter (2020): 6.

24. Decroly E., et al. "Coronavirus non-structural protein 16 is a cap-0-binding enzyme possessing Nucleoside-2'-0)-methyltransferase activity". Journal of Virology 82.16 (2008): 80718084 .

25. Ferron F., et al. "The viral RNA capping machinery as a target for antiviral drugs". Antiviral Research 96 (2012): 21-31.

26. Bollati M., et al. "Recognition of RNA cap in the Wesselsbron virus NS5 methyltransferase domain: implications for RNAcapping mechanisms in Flavivirus". Journal of Molecular Biology 385 (2009): 140-152.

27. Zust R., et al. "Ribose 2'-O-methylation provides a molecular signature for the distinction of self and non-self mRNA dependent on the RNA sensor Mda5". Nature Immunology 12 (2011): 137-143.

28. Premkumar A., et al. "Cation-selective ion channels formed by $\mathrm{p} 7$ of hepatitis $\mathrm{C}$ virus are blocked by hexamethylene amiloride". FEBS Letters 557.1-3 (2004): 99-103.

29. Pham T., et al. "The rotavirus NSP4 viroporin domain is a calcium-conducting ion channel". Scientific Reports 7 (2017): 43487.

30. Schoeman D and Fielding BC. "Coronavirus envelope protein: current knowledge". Virology Journal 16.1 (2019): 69.

31. Ulasli M., et al. "The effects of Nigella sativa (Ns), Anthemis hyalina (Ah) and Citrus sinensis (Cs) extracts on the replication of coronavirus and the expression of TRP genes family". Molecular Biology Reports 41.3 (2014):1703-1711.

32. Kilianski A and Baker SC. "Cell-based antiviral screening against coronaviruses: Developing virus-specific and broadspectrum inhibitors". Antiviral Research 101 (2014): 105-112.

33. De Wilde AH., et al. "Host Factors in Coronavirus Replication". Current Topics in Microbiology and Immunology 419 (2018): 1-42.

34. De Wilde AH., et al. "Alisporivir inhibits MERS- and SARS-coronavirus replication in cell culture, but not SARS coronavirus infection in a mouse model". Virus Research 228 (2017): 7-13.

35. Prentice E., et al. "Coronavirus replication complex formation utilizes components of cellular autophagy". Journal of Biological Chemistry 279.11 (2004): 10136-10141.
36. Chakraborty AK. "Heterogeneous phyto-antibiotics and other future therapeutics against multi-drug resistant bacteria". $A d$ vances in Biochemical 7.2 (2019): 34-50.

37. Newman DJ and Cragg GM. "Natural products as sources of new drugs over the 30 years from 1981 to 2010". Journal of Natural Products 75.3 (2012): 311-335.

38. Chakraborty AK., et al. "Multidrug- Resistant Bacteria with activated and diversified MDR Genes in Kolkata Water: Ganga Action Plan and Heterogeneous Phyto-Antibiotics tackling superbug spread in India". American Journal of Advanced Drug Delivery 5.1 (2018): 1-9.

39. Chakraborty AK. "Nucleic-Acids Based Nanocarriers". In: "Nanocarriers for Drug Delivery". editions. Mahapatra., et al. chapter-5 (2018): 155-172.

40. Tan Y-J., et al. "Overexpression of 7a, a protein specifically encoded by the severe acute respiratory syndrome coronavirus, induces apoptosis via a caspase-dependent pathway". Journal of Virology 78.24 (2004): 14043-14047.

41. Falzarano D., et al. " Treatment with interferon-alpha2b and ribavirin improves outcome in MERS-CoV-infected rhesus macaques". Nature Medicine 19 (2013): 1313-1317.

42. Cao J., et al. "A screen of the NIH Clinical Collection small molecule library identifies potential anti-coronavirus drugs". Antiviral Research 114 (2015): 1-10.

43. Mao X., et al. "Yeast mRNA cap methyltransferase is a 50-kilodalton protein encoded by an essential gene". Molecular and Cellular Biology 15 (1995): 4167-4174.

44. Rother M., et al. "Mode RNA: a tool for comparative modeling of RNA 3D structure". Nucleic Acids Research 39 (2011): $4007-$ 4022.

45. Surya W., et al. "MERS coronavirus envelope protein has a single transmembrane domain that forms pentameric ion channels". Virus Research 201 (2015): 61-66.

\section{Assets from publication with us}

- Prompt Acknowledgement after receiving the article

- Thorough Double blinded peer review

- Rapid Publication

- Issue of Publication Certificate

- High visibility of your Published work

Website: https://www.actascientific.com/

Submit Article: https://www.actascientific.com/submission.php Email us: editor@actascientific.com Contact us: +919182824667 